$c>3$
3

$A G C--8207-64-2$ 


\section{DISCLAIMER}

This report was prepared as an account of work sponsored by an agency of the United States Government. Neither the United States Government nor any agency Thereof, nor any of their employees, makes any warranty, express or implied, or assumes any legal liability or responsibility for the accuracy, completeness, or usefulness of any information, apparatus, product, or process disclosed, or represents that its use would not infringe privately owned rights. Reference herein to any specific commercial product, process, or service by trade name, trademark, manufacturer, or otherwise does not necessarily constitute or imply its endorsement, recommendation, or favoring by the United States Government or any agency thereof. The views and opinions of authors expressed herein do not necessarily state or reflect those of the United States Government or any agency thereof. 


\section{DISCLAIMER}

Portions of this document may be illegible in electronic image products. Images are produced from the best available original document. 
Report No. 8207-64-2

\title{
Test Plan for Cryogenic Metallic Seals Tests
}

30 March 1964

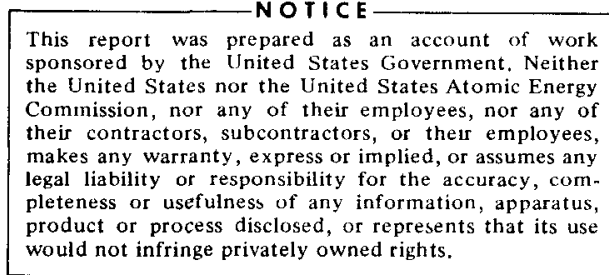

This report was prepared as an account of work Neither employees, would not infringe privately owned rights.

\author{
Contract SNP-1 \\ LRP NERVA Rocket Operations
}

The work specified in this document is being performed as part of the engineering complex of sub-subtask 1.4.3, Pressure Vessel. 
DOCUMENT APPROVAL SIGNATURES

Prepared By:

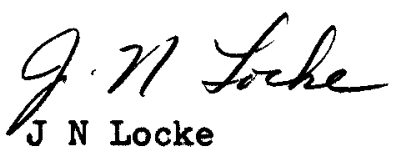

Thrust Chamber Assy Dept

Component Development

Approved By:

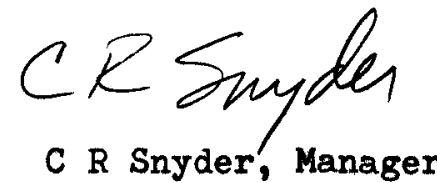

Thrust Chamber Assy Dept

Component Development
Dept

8200
Date

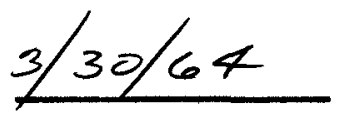




\section{TABLE OF CONTENTS}

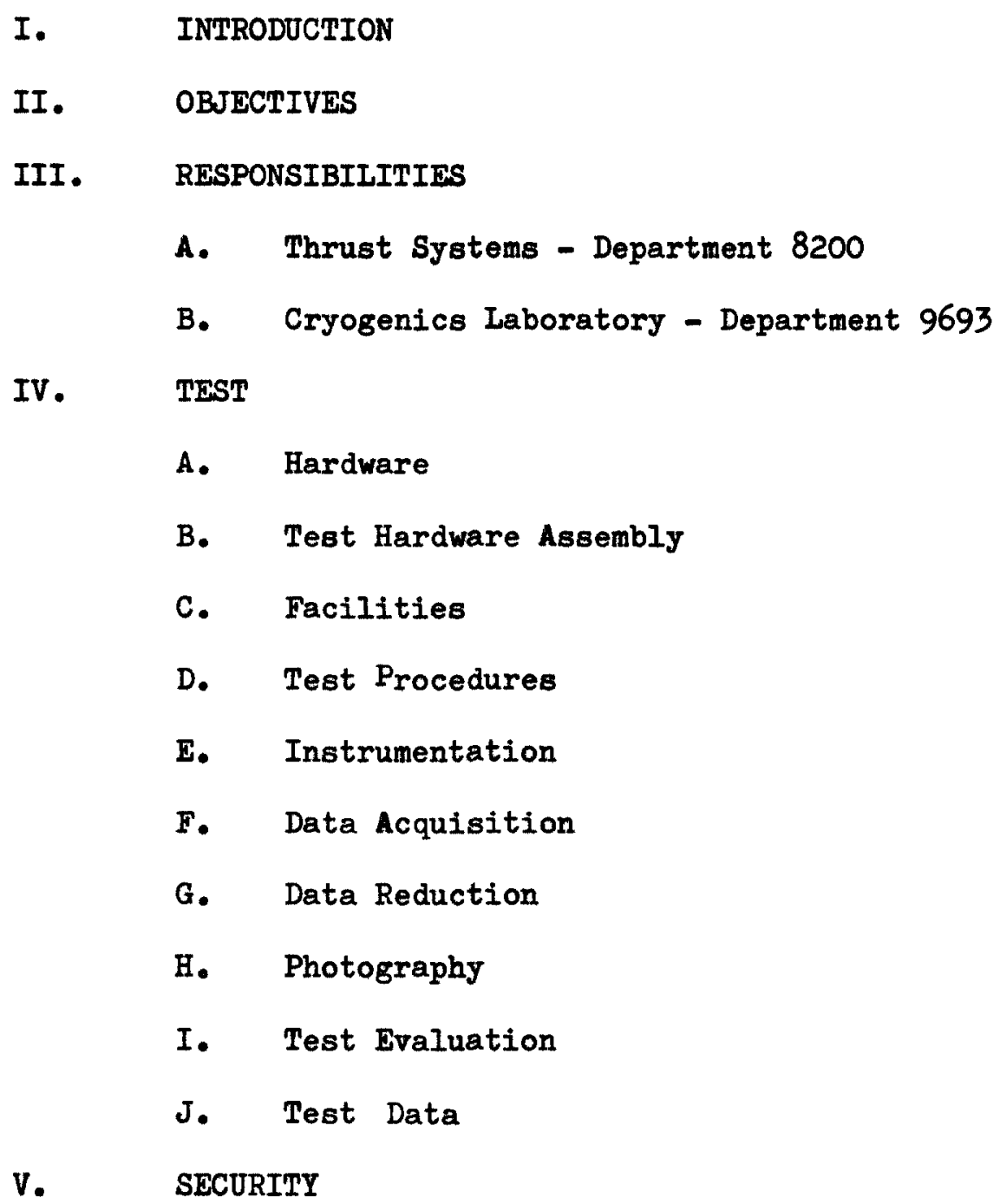


Page: 1

Prepared by: J N Locke

Date: 30 March 1964

Revision:

Approved by: C R Snyder

TEST PLAN FOR CRYOGENIC METALLIC SEALS TEST

I. INTRODUCTION

This document describes the test plan for cryogenic testing of metallic seals designed for use in NERVA pressure vessel joints. The tests will be conducted using a seal test vessel with internal volume displacement to maintain minimum gas energy. The tests will serve as a means of evaluating leakage for comparison with the maximum permissible leakage of $10^{-2}$ standard cubic centimeters per second per inch of diameter ${ }^{(1)}$. The tests will be performed at ambient and at minus $300 \pm 20^{\circ} \mathrm{F}$ using a helium and a hydrogen testing medium. Due to the security classification of the pressures, the values will be supplied under separate cover.

The work specified under this document is being performed as part of sub-subtask 1.4 .3 - PRESSURE VESSEL.

II. OBJECTIVE

The primary objective of this test is to evaluate the ability of the pressure vessel seals to limit helium and hydrogen gas leakage to less than $10^{-2}$ STD cc/sec-in. dia.

III. RESPONSIBILITIES

A. Thrust Chamber Assy - Department 8200

1. Prepare and approve the test plan and all subsequent changes.

2. Establish test pressures.

3. Provide seal test vessel, seals, and seal test vessel core。

(1) NERVA Design Criteria, Pressure Vessel Assembly, Hydrogen, for NRX-A Reactor Test Assemblies, 25 February 1964 (S-RD). 
Page: 2

Prepared by: J N Locke

Date: 30 March 1964

Revision :

Approved by: C R Snyder

\section{TEST PLAN FOR CRYOGENIC METALLIC SEALS TEST}

4. Provide bolts, washers and closure plugs for the seal

test ressel.

5. Coordinate activities.

6. Approve all procedures.

7. Follow component assembly.

8. Analyze and evaluate test data.

9. Prepare, approve and submit final test report.

10. Coordinate inspection of test hardware and test specimens.

B. Cryogenies Laboratory - Department 9763.

1. Establish a test schedule.

2. Provide the test facilities.

3. Design and fabricate special test fixtures, tooling,

and related equipment as required.

4. Perform testing and acquire data.

5. Evaluate data for reliability and accuracy.

6. Transmit test data to Department 8200 .

7. Provide a stand which will position and hold down the test ressel.

IV. TEST

A. Hardware

The test specimens will be pressure vessel Seals $P / N 702153$. Test hardware consists of Mockup Cylinder P/N 296995, Closure P/N 298252, and volume displacing core $\mathrm{P} / \mathrm{N}$ 705615-9, 120 A286 Bolt s,P/N 28664-1 and 120 washers P/N SPS 39969-WC $-22-10$. The volume displacing core listed above 
Page: 3

Date: $\quad 30$ March 1964
Prepared by: J N Locke

Approved by: C R Snyder

\section{TEST PLAN FOR CRYOGENIC METALLIC SEALS TEST}

is required so that compressed gas energy is kept within safe limits. Standard adapters, fittings, 0-rings, bolts and washers will be available to seal the control rod drums and instrumentation ports.

B. Test Hardware Assembly

1. Attach twelve port plugs (T-41719-9) torquing 48 to 52 ft-lbs using seals $\mathrm{P} / \mathrm{N} 263856$, and "Marman Clamps (50773-H-250) torqued 90-95 in-lbs, to the applicable flanged ports of the closure (298252).

2. Thread ten port plugs $(T-417202-2)$ with two (2) port plugs (T-417202-1 port plugs with $1 \%$ inch thru hole piping connections) at opposite locations with twelve O-rings (ASI119-JI-32) into the applicable threaded ports of closure, two Oarings (ASIII9-J1-20 for the piping connections) are required for 1 port plugs.

3. Attach Pressure Plate P/N TE-5097 with O-ring AS118-oJ1237 using six 3/8-24 $\times 1 \%$ cap screws and flat washers on the dome end of seal test vessel cylinder.

4. Place the seal test vessel holding frame within the confines of the coolant tank and then place the seal test vessel cylinder (296995) in the holding frame with its flanged end upward.

5. Carefully install the seal test vessel core (705615-9) inside the cylinder with special attention to protection of the seal gland surface.

6. The cylinder and closure mating seal surfaces shall then be cleaned in accordance with the following: 
Sealing surfaces shall be cleaned with trichloroethylene (TRICO) using clean rags. After cleaning with TRICO, the sealing surfaces shall be polished with \#900 laping compound, produced by Diesel Control Corp, Wilmington, California, or an equivalent, such as $-3 \mathrm{~A}$ micron aluminum oxide metallographic polishing compound manufactured by the Linde Company. The polishing shall be performed with soft clean rags with rubbing pressure applied by hand only, no instruments or tools are to be used as backup to the rag. The polishing compound must be applied sparingly with a heavy rubbing action applied. After polishing with the compound is completed, the grooves and sealing surfaces shall be cleaned with TRICO using clean rags; particular care must be taken "to clean all" polishing compound residue from the seal groove corners and from bolt holes. Clean all bolt thread inserts on the test vessel cylinder flange with trichloroethylene.

7. After thorough cleaning of the bolts with trichloroethylene place a very thin strip of IED PIATE 250 thread lubricant on each bolt thread insert in the cylinder joint and also a coating of lubricant shall be placed under the head of each bolt prior to assembly with the washer。

8. Remove a seal (test specimen) from its container and place in the seal gland of the seal test vessel in accordance with the following instructions:

When removing a seal from its shipping container, no tools or instruments shall be placed in contact with it. Use clean rubber or clean soft cloth gloves when handing the seals directlyo special care should be taken in positioning the seal in the cylinder seal gland to make 
Page: 5

Date: 30 March 1964

Prepared by: J N Locke

Revision:

Approved by: C R Snyder

TEST PLAN FOR CRYOGENIC METALLIC SEAL TEST

sure none of the seals inner lip overlaps the chamfer of the inside diameter of the seal gland. Once the seal has been hand placed into its seal gland the mating part (Closure 298252) shall be moved by use of a Multiple Leg Sling $P / N 278580$, a Lifting Fixture $P / N 279150$, and twelve MS 35305-10 Bolts AN 960 C416 washers torqued to 95-115 inch-1bs washers into position (note index pins) to within $1 / 4$ inch of seating position. Bolts P/N 286664 and washers SPS 39969-WC-22-10 at eight equally spaced positions should then be started in their respective holes to help position the mating surfaces in parallel planes. Then the bolts shall be tightened gradually keeping the joint gap approximately equal around the periphery; the engaged bolts will help stop angular rotation during joint mating. Once the joint is closed by gradually tightening bolts by opposite pairs simultaneously the balance of the bolts shall be installed and torqued in pairs in $25 \%$ increments to the maximum torque value of the $160 \mathrm{ft}+\mathrm{lbs}$ 。

9. The periphery of the joint and the pilot holes in the cylinder flange shall be taped or sealed by glass fabric tape, such as "Tuck Tape"。

10. The leakage collection line will then be assembled and installed. The leakage collection line and the sealed areas (See Step \#9) will then be leak checked by "sniffer" or bubble solution when back pressurized to 1.0 to 2.0 psig. Any leakages found will be corrected and rechecked until no losses can occur。

11. Coolant feed line plumbing will then be installed and leak checked as required。 Test gas lines (helium-hydrogen) will then be assembled and installed with leak checks performed。 
Page: 6

Prepared by: J N Locke

Date: 30 March 1964

Revision:

Approved by: C R Snyder

TEST PLAN FOR CRYOGENIC METALLIC SEALS TEST

12. Exterior insulation will be applied as determined and

directed by Department 9763.

C. Facilities

Test Facilities will be determined by Department 9763

subject to the approval of Department 8200 .

D. Test Procedures

1. Component Inspection

The pressure vessel axial and diametral measurements

as shown in Figure 1 shall be inspected and recorded prior to assembly. The seal dimensions shall be measured and recorded as shown in Figure 2. Careful seal handling is mandatory to protect the lead surface plating.

2. Test

Leakage shall be determined by the use of a Hastings

Mass Flow Meter backed up with water displacement on the helium tests. With the test vessel fully assembled and ready for chilling a series of

pressurization cycles will be made at ambient temperature conditions. Three pressurizations cycles pressurizing with gaseous helium recording data at $20,40,50,60,70,80,90$ and 100\%* of maximum test pressure will be performed. Three pressurization cycles will then be made using gaseous hydrogen recording leakage data at the pressure increments listed above. Interior seal test vessel temperature shall be monitored and recorded when recording leakage at the above data points.

* One hundred percent test pressure, which is classified as CONFIDENTIAL, will be forwarded under separate cover. 
Page: 7

Date: 30 March 1964

Prepared by: I N Locke

TEST PLAN FOR CRYOGENIC METALLIC SEALS TEST

Iiquid nitrogen shall then be introduced into the

coolant container surrounding the seal test vessel and filled to above the

flanged joint of the seal test vessel. After sufficient cool down time has

elapsed (temperature sensing instrumentation within the seal test vessel

indicating $-300 \pm 20^{\circ} \mathrm{F}$ for five minutes) three pressurization cycles shall

be performed using gaseous helium and recording leakage and temperature data.

After gaseous helium tests have been completed gaseous hydrogen will be

introduced at test medium and three additional pressurizations made

recording data at the same increments as above.

Pressure in the pressure vessel will be applied in

the following manner: Pressurize at 150 to $200 \mathrm{psig} / \mathrm{minute}$ to the selected pressure increments and hold while leakage measurements are recorded and then continue pressurizing until all steps are completed. Appropriate control is to be maintained to prevent an increase in pressure above the maximum. After test completion, disassembly will be made to install other test specimens and reassembly will be made beginning with Item No. 4 of Test Hardware Assembly。

After the test series has been completed the pressure vessel is to be cleaned as required. Department 8200 will supply direction for disposition of the test components。 Test fittings, adapters, plugs, tooling and fixtures, and closure to cylinder bolts, will be cleaned and packed for shipment as determined by Departments 8200 and 9763.

E. Instrumentation

Leakage measurement shall be from two leakage collection holes, 
Page : 8

Prepared by: J N Locke

Date: 30 March 1964

Revision:

Approved by: C R Snyder

\section{TEST PLAN FOR CRYOGENIC METALIIC SEALS TEST}

one which will be in the flange of the seal test vessel cylinder, the other in the flange of the closure, see Figure 3 .

Temperature sensing instrumentation shall be located at

four equally spaced locations inside the seal test ressel adjacent to the

seal gland.

Pressure sensing instrumentation shall be placed on the test

gas (helium or hydrogen) inlet line near the closure connection.

F. Data Acquisition

The following measurements will be made:

1. Pressure vs time.

2. Temperature of test vessel vs time.

3. Pressure and temperature during leakage measurement.

4. Leakage vs pressure。

G. Data Reduction

The following information will be prepared:

1. Pressure vs time profiles

2. Leakage rate, if any, vs pressure

H. Photograph

Still photographs will be taken showing, as a minimum, the

following:

1. Test Setup.

2. Leakage measurement equipment。

3. Temperature and pressure measurement equipment。

I. Test Evaluation 
Page: 9

Prepared by: J N Locke

Date: 30 March 1964

Revision:

Approved by: C R Snyder

TEST PLAN FOR CRYOGENIC METALLIC SEALS TEST

An evaluation of the test by representatives of Department

8200 and 9763 will be made within a day following the test series

completion to investigate any unusual results which would require any further testing.

\section{J. Test Data}

Test Data shall be transmitted to Department 8200 by

Department 9763 within ten working days following test series completion and shall include:

1. Test engineer's submittal including deviations from

the test plan, problems encountered and recommendations。

2. Test log with primary emphasis on actual events during

the test.

3. Data as required in paragraph $F$ and $G_{\text {. }}$

4. Test photographs of the test setup leakage measurement

assembly。

5. Equipment and instrumentation.

6. Location of instrumentation as placed.

7. Evaluation of the data reliability and accuracy.

A test report will be prepared by Department 8207 within

sixty working days of test series completion. This report will include:

1. Statement of test objectives。

2. Summarize significant events occurring during the test。

3. Present significant data as may be available. 
Page: 10

Prepared by: J N Locke

Date: 30 March 1964

Revision:

Approved by: C R Snyder

TEST PLAN FOR CRYOGENIC METALLIC SEALS TEST

4. Discussion and preliminary conclusions on

accomplishments of test objectives.

5. Recommendations as required.

V. SECURITY

Due to the classification of test pressure, the record shall

refer to percentages of test pressure. The classified memorandum specifying

the ambient proof pressure shall be referenced on each record. 
Prepared by: J N Locke

Page 11

Approved by: C R Snyder

FIGURE 1

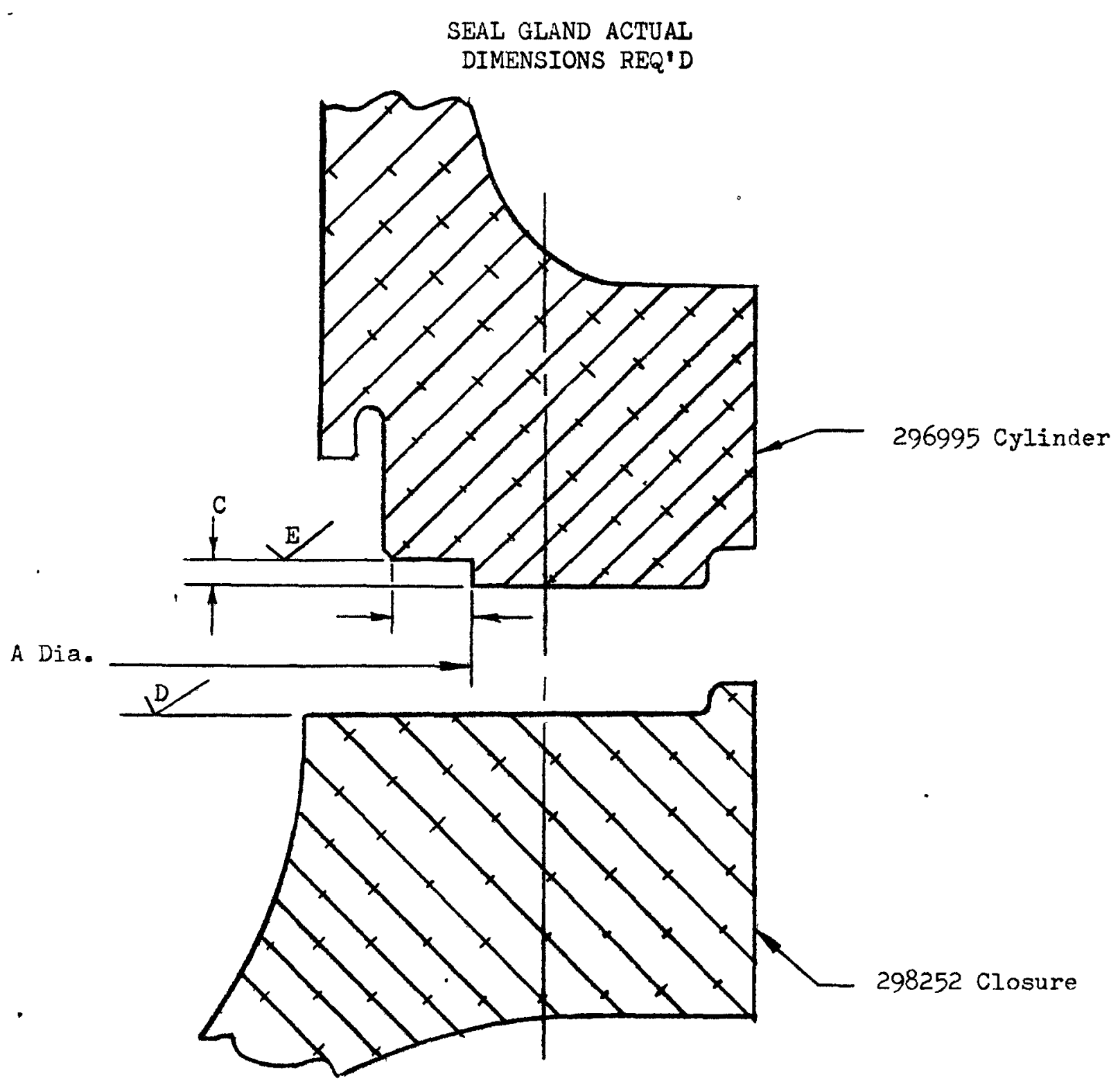

\begin{tabular}{|c|c|c|c|c|}
\hline $\begin{array}{c}\text { Anch } \\
\text { Dia. }\end{array}$ & $\begin{array}{c}\text { B } \\
\text { Inches }\end{array}$ & $\begin{array}{c}\text { C } \\
\text { Inches }\end{array}$ & $\begin{array}{c}\text { D } \\
\text { Surface } \\
\text { Roughness }\end{array}$ & $\begin{array}{c}E \\
\text { Surface } \\
\text { Roughness }\end{array}$ \\
\hline & & & & \\
\hline
\end{tabular}


Prepared by: J N Locke

Page 12

Approved by: C R Snyder

FIGURE 2

SEAL ACTUAI DIMENSIONS

REQUIRED

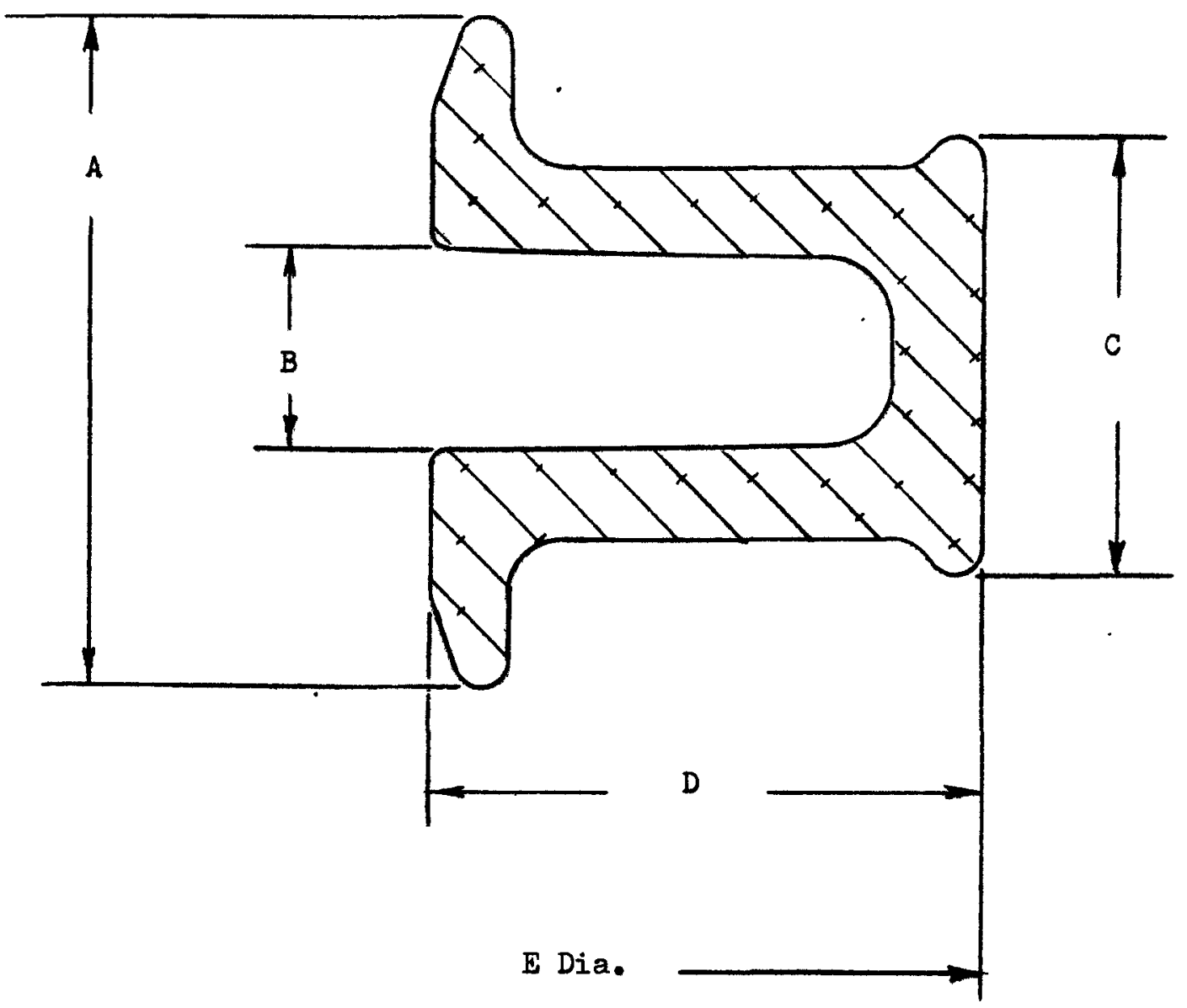

\begin{tabular}{|c|c|c|c|c|}
\hline $\begin{array}{c}\text { A } \\
\text { Inches }\end{array}$ & $\begin{array}{c}\text { B } \\
\text { Inches }\end{array}$ & $\begin{array}{c}\text { C } \\
\text { Inches }\end{array}$ & $\begin{array}{c}\text { D } \\
\text { Inches }\end{array}$ & $\begin{array}{c}E \\
\text { Inches Dia }\end{array}$ \\
\hline & & & & \\
\hline
\end{tabular}


FIGURE 3

\section{LEAKAGE COLLECTION}

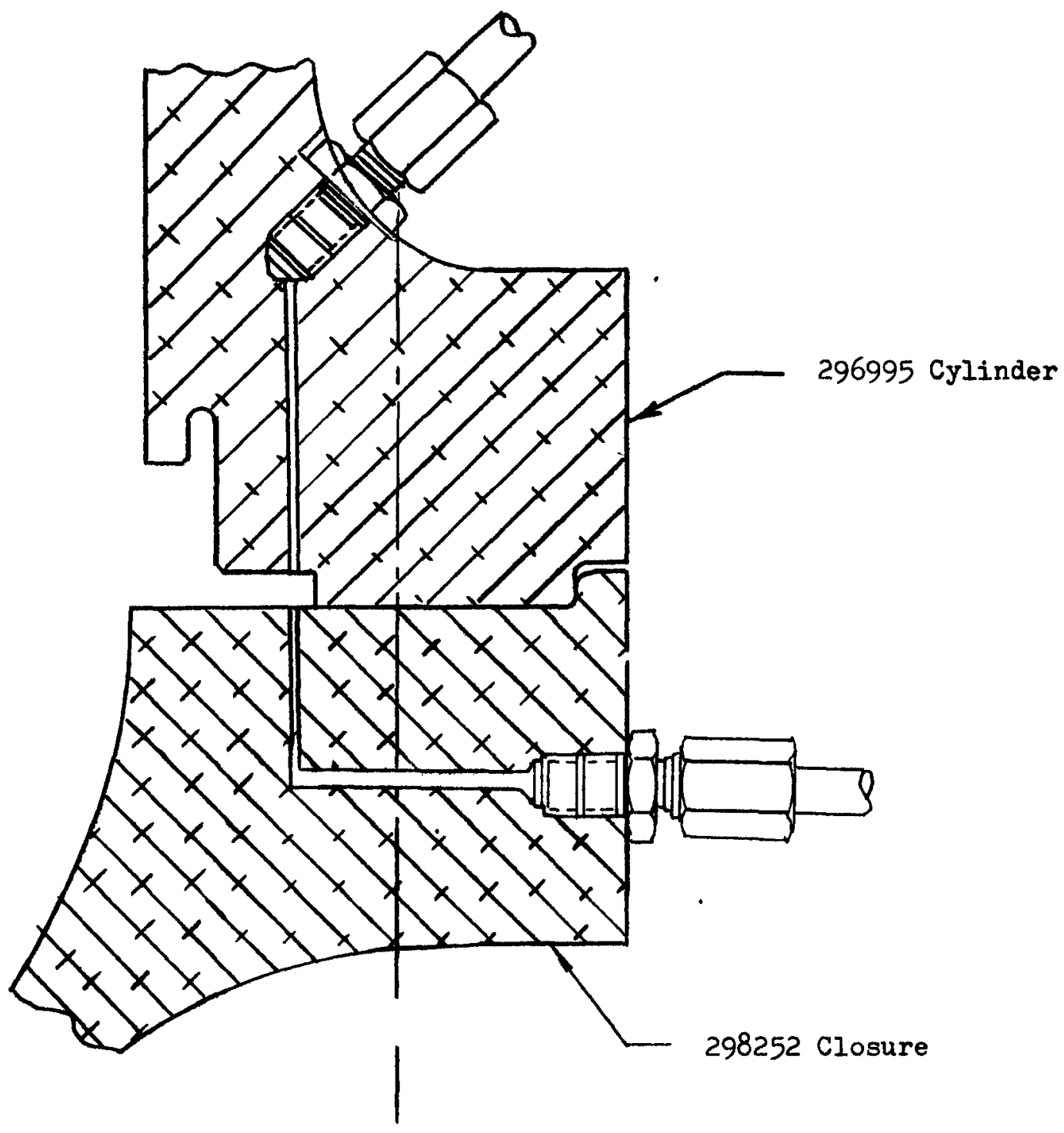


Page 14

\section{FIGURE 4}

SCHEMATIC OF TEST

SET UP

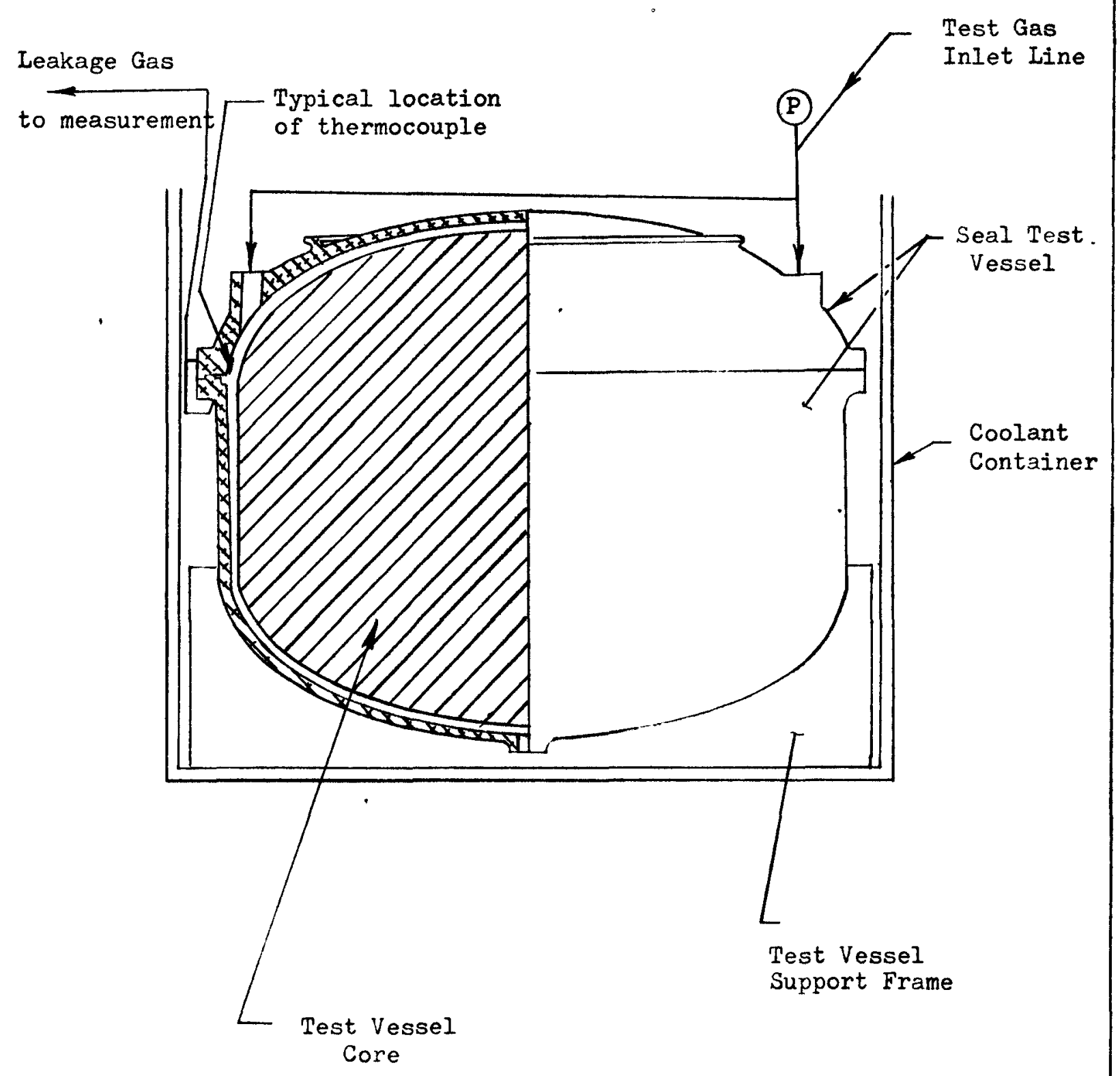




\section{AEROJET-GENERAL CORPORATION}

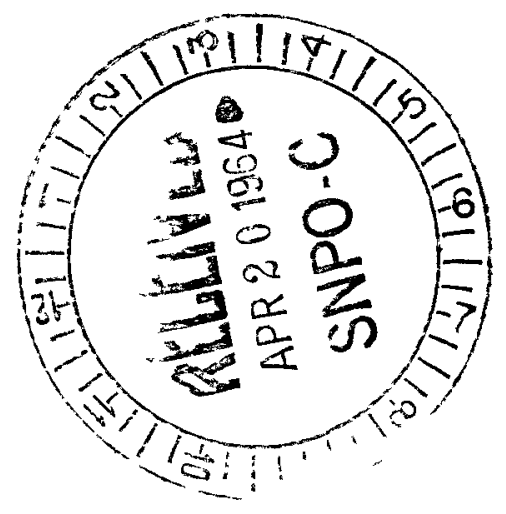

